Journal of Engineering and Applied Sciences 14 (12): 4167-4175, 2019

ISSN: 1816-949X

(C) Medwell Journals, 2019

\title{
Social Media Mining: Analysis of Twitter Data to Find user Opinions about GST
}

\author{
${ }^{1} \mathrm{~K}$. Jayamalini and ${ }^{2} \mathrm{M}$. Ponnavaikko \\ ${ }^{1}$ Department of Computer Science Engineering, Bharath University, Chennai, India \\ ${ }^{2}$ Vinayaka Mission's Research Foundation, AV Campus, Chennai, India
}

\begin{abstract}
Twitter is a social networking and micro blogging service, enabling registered users to read and post short messages, called "Tweets". Length of Tweets are limited to 140 characters. Twitter allows users to post photos or short videos. Twitter is one of the most popular social networking site, used by people across the world for rapid communication and information exchange. Everyday, about 330 million active users use Twitter to share information and express their opinion. Every second on average, around study 6,000 study Tweets are published on Twitter which corresponds to over study 350,000 study Tweets sent per minute, study 500 million study Tweets per day and around study 200 billion study Tweets per year. The volume and variety of data generated by social media helps businesses in their decision-making. It also helps celebrities in the film industry, sports and politics to find user opinion about them. Currently, opinion mining and sentiment analysis is an emerging area for researchers due to ready availability of opinionated data on social networking sites, review sites and blogs. This data helps in finding different types of sentiments and opinions towards a particular event or things. Summarizing these opinions can provide valuable insights for businesses. Analysis of opinions and its classification based on polarity is a challenging task. This study, explains various sentiment analysis techniques on Twitter data by taking user Tweets about Goods and Services Tax (GST). This study illustrates the dictionary based approach along with NLP which was used to find the polarity of the Tweets and classify them.
\end{abstract}

Key words: Sentiment analysis, opinion mining, social networks analysis, Tweets, NLP, GST and R

\section{INTRODUCTION}

Twitter is a hugely popular social media platform for expressing our emotions, opinions and activities. Twitter consists of massive amount of information that is available on the web. Today, the structured as well as unstructured data on the internet (Lin et al., 2014) is increasing at a rapid pace. Industries, companies and businesses are using this tremendous amount of structured, unstructured and semi structured data available on social media to gain insight into people's views and opinions about their products and services. This would be a powerful tool to keep the company ahead of competition. Social media is a critical source to extract the opinions of end users and more importantly, the emotions attached to how users perceive the products and services. Analysis of this data would be virtually impossible if done manually.

Twitter is one of the most popular online platforms and social media network that allows people to share information. It allows registered users to view and post their own Tweets. Tweets are restricted to 140 characters. Registered users can express their opinion by posting Tweets or by uploading photos or short videos. They can also re-tweet the Tweets posted by other users. Unregistered users have rights to read the Tweets. Currently, Twitter has 330 million active users. Every second, an average of 6,000 Tweets are Tweeted on Twitter which is equal to around 360,000 Tweets per minute, study 500 million Tweets per day study and around 200 billion Tweets per year.

In recent years, Tweets and re-tweets posted by users have become a tool to gauge user opinions about products, people, government policies and national and international issues. Top government officials and many celebrities in the fields of politics, film industry and sports use Twitter data to find public opinion about them. Performing sentiment analysis on stream of Twitter data finds the polarity value for each Tweet in the stream and classifies them into positive, negative and neutral. This study deals in depth with the sentiment analysis on Twitter data to discover user opinions about GST as a case study.

GST Thowseaf and Millath (2016) is a taxation procedure for goods and services transported from one destination to another. It is an study indirect tax study levied in study India study on the sale of goods and services. Goods and services are divided into five tax

Corresponding Author: K. Jayamalini, Department of Computer Science Engineering, Bharath University, Chennai, India 
slabs for collection of tax $-0,5,12,18$ and $28 \%$. The tax came into effect from July 1, 2017, through the implementation of study one hundred and First Amendment of the Constitution of India study by the Government of India. The tax replaced existing multiple cascading taxes levied by the central and state governments. Taxation and its associated governing laws, plays a significant role in the life of business, its impact on the individual and on government policies for social good.

\section{Literature review:}

Previous work: The rapid growth and population of blogs and social media networks (Singh and Dubey, 2014) make the field of opinion mining and sentiment analysis an interesting field for researchers. Jansen et al. (2009) explains the facts, methods, data sources and various algorithms used in the field of opinion mining. Wu et al. (2015) describes the algorithmic analysis of the sentiment of e-micro-blogs covering about 50 brands and categorizes them to determine the aggregate characteristics of the brand. Study by Barnaghi et al. (2016), describes a computational pipeline for collecting, processing and analyzing Tweets to find signals about adverse drug reactions (drug side effects caused by a drug at a normal dose during normal use) using NLP. Study by Lin et al. (2014), presents an objective to use Twitter streaming API and official world cup hash tags to mine, filter and process Tweets in order to analyze the reflection of public sentiment towards unexpected events using SVM machine learning classifier. Wang and Gan (2017) proposes an efficient method to mine and summarize opinions collected by Weibo, a Twitter-like micro blog service in China. Study by Fernandes and D'Souza (2016), explains how Twitter sentiment analysis was used as a tool to predict the French General Elections in 2017.

$\mathbf{R}$ and $\mathbf{R}$ tool: $\mathrm{R}$ is a programming language and free software environment for statistical computing and graphics supported by the R Foundation for Statistical Computing. The $\mathrm{R}$ language is widely used among statisticians and data miners for developing statistical software and data analysis. Polls, surveys of data miners and studies of scholarly literature databases show that $R$ 's popularity has increased substantially in recent years.

$\mathrm{R}$ is a programming language and software environment intended for deep statistical computing and graphics. It is open source and available across different platforms, e.g., Windows, Mac, Linux. It is used in a variety of applications including visualizations and data mining.

\section{MATERIALS AND METHODS}

Overview of the system architcture: This study explains the complete approach and various steps used in the Twitter opinion miner. The framework of opinion analyzer to analyze the user opinions towards a specific issue is depicted in Fig. 1. The nature of data extracted from Twitter may bein a structured format, semi-structured format or unstructured format. The framework comprises of Tweets extractor, preprocessor, feature extractor, opinion value calculator, opinion classifier. The methods (Patil et al., 2017) involved in the development of Twitter data opinion miner are explained as:

$\begin{array}{ll}\text {. } & \text { Tweets extraction and data collection } \\ \text {. } & \text { Tweets preprocessing } \\ \text {. } & \text { Feature extraction } \\ \text {. } & \text { Opinion analysis } \\ \text {. Opinion identification and value calculation } \\ \text {. Opinion classification } \\ \text {. Opinion summarization } \\ \text {. Opinion visualization }\end{array}$

The extractor connects to Twitter and extracts specific Tweets based on given search keyword. The data collected from Twitter contain irrelevant and noisy information. This irrelevant and noisy information has to be cleaned before it is used by other parts of the system. The preprocessed Tweets were categorized into positive, negative or neutral by the opinion analyzer.

Extraction of Tweets: Twitter is an amazing social media network for text analysis, sentiment analysis and social web analysis. Different types of software provide different ways to extract data from Twitter. Among all, R offers wide-ranging choices to do many interesting things.

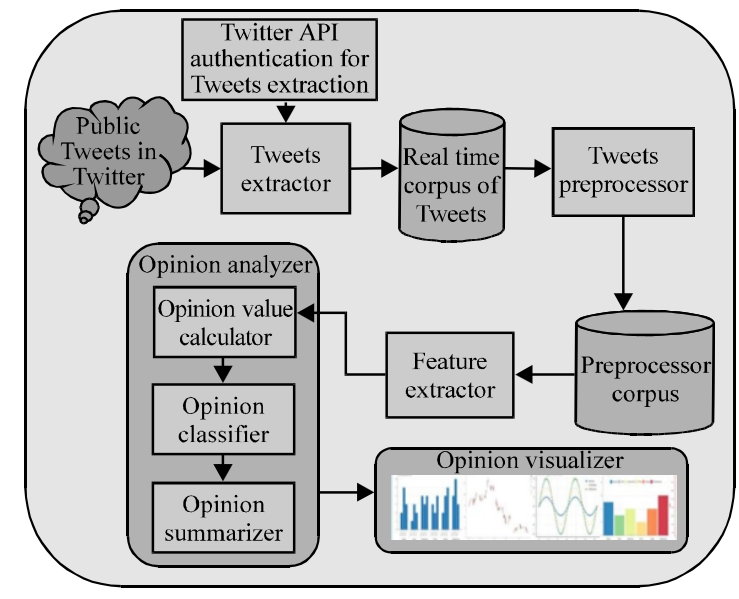

Fig. 1: Architecture-Twitter data opinion analyzer 


\begin{tabular}{|c|c|c|c|c|c|c|c|c|c|c|c|c|c|c|c|}
\hline Created & $\begin{array}{l}\text { Fav orit } \\
\text { count }\end{array}$ & Favorited & Id & $\begin{array}{l}\text { Is } \\
\text { retweet }\end{array}$ & Latitued & Longitude & $\begin{array}{l}\text { Reply } \\
\text { to SID }\end{array}$ & $\begin{array}{l}\text { Reply } \\
\text { to SN }\end{array}$ & $\begin{array}{l}\text { Reply } \\
\text { to UID }\end{array}$ & $\begin{array}{l}\text { Retweet } \\
\text { count }\end{array}$ & Retweeted & $\begin{array}{l}\text { Screen } \\
\text { name }\end{array}$ & $\begin{array}{l}\text { Status } \\
\text { source }\end{array}$ & Text & Truncated \\
\hline $\begin{array}{l}06 / 12 \\
2017\end{array}$ & 0 & False & $\begin{array}{l}9.3845 \\
E+17\end{array}$ & True & NA & NA & NA & NA & NA & 127 & False & $\begin{array}{l}\text { Amitsoni } \\
\text { Nawab }\end{array}$ & $\begin{array}{l}<a \text { herf } \\
=" \text { http }\end{array}$ & $\begin{array}{l}\text { Rt @bhatia_niraj23: He is } \\
\text { suresh tanna, asmall businessman.. } \\
\text { has faced great slowdown after } \\
\text { noteban and amp; GST... he has faith } \\
\text { in @office of RG and amp;... }\end{array}$ & False \\
\hline $\begin{array}{l}06 / 12 \\
2017\end{array}$ & 0 & False & $\begin{array}{l}9.3845 \\
E+17\end{array}$ & True & NA & NA & NA & NA & NA & 37 & False & Sss7 rym & $\begin{array}{l}<a \text { herf } \\
=" \text { http }\end{array}$ & $\begin{array}{l}\text { RT @ptrmadurai: } 6 \text { years of ADMK } \\
\text { Govt, capped by a disastrous GST } \\
\text { implemention have seriously damaged } \\
\text { TN's industrial growth. This article... }\end{array}$ & False \\
\hline $\begin{array}{l}06 / 12 \\
2017\end{array}$ & 0 & False & $\begin{array}{l}9.3845 \\
E+17\end{array}$ & $\begin{array}{l}\text { True } \\
\text { True }\end{array}$ & NA & NA & NA & NA & NA & 21 & False & $\begin{array}{l}\text { Anilbudhwar } \\
1\end{array}$ & $<$ a herf & $\begin{array}{l}\text { RT @ ashokgehlot 51: five quarters of } \\
\text { slowdown in GDP growth are an } \\
\text { indication that both \#DeMonetisation } \\
\text { and modi government' s\# GST proved to }\end{array}$ & False \\
\hline $\begin{array}{l}06 / 12 \\
2017\end{array}$ & 0 & False & $\begin{array}{l}9.3845 \\
E+17\end{array}$ & True & NA & NA & NA & NA & NA & 88 & False & $\begin{array}{l}\text { Amitsoni } \\
\text { Nawab }\end{array}$ & $\begin{array}{l}<a \text { herf } \\
=" \text { http }\end{array}$ & $\begin{array}{l}\text { RT @kukk 44: this is not GST, this is } \\
\text { gabbar singh tax. Its aim is to take away } \\
\text { your hard earned money. \#<U+0A95 } 4 \mathrm{U} \\
+0 \mathrm{ABC} \times \mathrm{U}+0 \mathrm{~A} 82 \times \mathrm{U}+0 \mathrm{~A} 97 \times \mathrm{U}+0 \mathrm{ACD} \times\end{array}$ & False \\
\hline $\begin{array}{l}06 / 12 \\
2017\end{array}$ & 0 & False & $\begin{array}{l}9.3845 \\
E+17\end{array}$ & True & NA & NA & NA & NA & NA & 13 & False & $\begin{array}{l}\text { Briansequeira } \\
05\end{array}$ & $\begin{array}{l}<\text { < herf } \\
=" \text { http }\end{array}$ & $\begin{array}{l}\text { RT@ @livemint: gujarat elections: } \\
\text { saurashtra traders miffed after GST } \\
\text { nixes 'kutcha' transactions https://t.co/ } \\
\text { PJRFe 5J2MC }\end{array}$ & False \\
\hline
\end{tabular}

To extract tweets from Twitter, a Twitter application should be created which will use the Twitter API to make the connection. The Twitter application will provide the authentication to the system and create your application's consumer key, consumer secret, access token and access token secret. Then, these details will be used in coding to connect and extract data from Twitter.

In Twitter, we can extract Tweets for specific purposes because it provides search based on specific keywords or hash tags. Using search keyword technique Tweets related to GST were collected and stored for analysis. Table 1 shows snapshot of Tweets related to GST extracted using Twitter API. The extracted Tweets were stored in GST_stack corpus.

Tweets preprocessing: The data collected from Twitter contain irrelevant and noisy information (Patil et al., 2017) which requires a cleanup before further usage. The pre-processor is used for:

. Removal of non-English letters, duplicate Tweets, URLs

- Removal of special characters, punctuation and white spaces and stop words

. Stemming and spell checking

- Lower case conversion and replacement of slang with original words

. Tokenization and separation of folksonomies

The flowchart of pre-processor is shown in Fig. 2. The extracted Tweets contains huge amount of additional meaningless information which will not add any value to the opinon analyzer. The extracted data contains the unwanted data in following fields:

- createdDate

. favoriteCount

. favorited

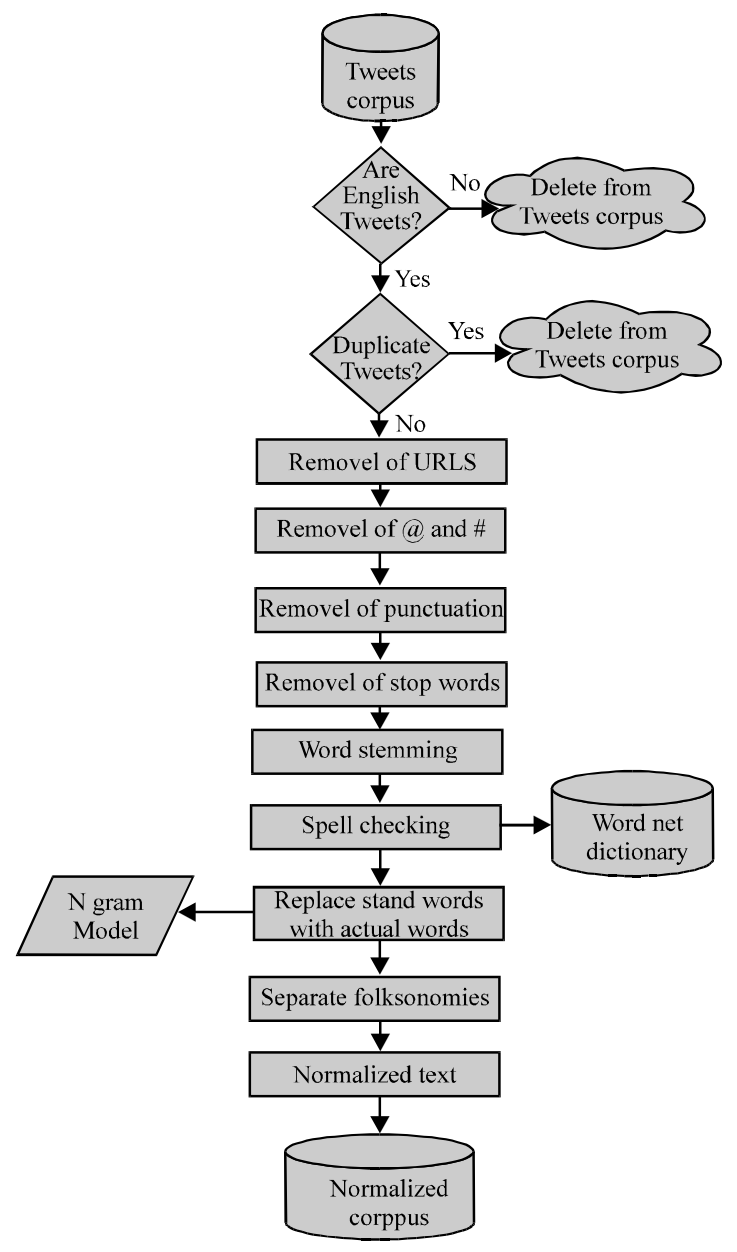

Fig. 2: Preprocessor of opinion analyzer

$\begin{array}{ll}\text {. } & \text { Tweets ID } \\ \text {. } & \text { isRetweet } \\ \text {. } & \text { latitude } \\ \text {. } & \text { longitude } \\ & \text { replyToSID }\end{array}$




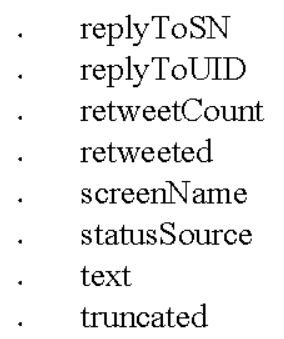

From the above fields, only "Text" field contains valid information which can be used by opinion analyzer to find the opinon. All other data are considered as noise and those data to be removed before processing. The preprocessor of opinion analyzer is used to remove the unnecessary data from the extracted Tweets corpus.

Feature extraction: The extracted Tweets contain the following attributes (11):

- Created date-UTC time (when the Tweet was created)

- Id-a sequence of integers to represent a unique key

. Id_str-string representation of the unique identifier

- Text-actual UTF-8 text posted by the user

- Source-utility used to post the Tweet

- Truncated-indicates whether the value of the study text study parameter was truncated or not

- User-user who posted this Tweet

- Coordinates represents the geographic location of this Tweet

- Place-indicates the place of Tweet

. Retweet_count the number of times Tweet has been retweeted

When the Tweets extractor of the system extract the Tweets, all the above attributes are stored in the corpus. Not all the above attributes will add any value to the opinion analyzer. The feature extractor was used to identify the most relevant attributes that contain valuable information. Only "Text" field contains valid information and the feature extractor extracts that field for further processing.

\section{Text}

Tweets after noise removal and feature extraction: $R T$ (a)bhatia niraj 23: he is Suresh Tanna, a small businessman has faced great slowdown after note ban and amp; GST he has faith in@Office of RG and amp

RT@ptrmadurai: 6 years of ADMK Govt, capped by a disastrous GST implementation have seriously damaged TN's industrial growth. This study

RT@ashokgehlot 51: five quarters of slowdown in GDP growth are an indication that both \#DeMonetisation and Modi government's \#GST proved to.
RT@kukk44: this is not GST, this is Gabbar Singh tax. Its aim is to take away your hard earned money. RT (a) livemint: Gujarat elections: Saurashtra traders miffed after GST nixes 'kutcha' transactions https:/t.co/ PJRFe5J2MC

Opinion analysis: The opinion analyzer of the system is divided into three parts as follows.

Opinion value calculator: Used to calculate the overall value of the sentence by comparing and assigning each word in the sentence, against a dictionary of positive words and negative words

Opinion classifier: Based on the value assigned to the sentences by the opinion value calculator, the sentences are classified into positive, negative or neutral

Opinion summarization: Used to summarize all the positive Tweets into one group, negative Tweets into the second group and neutral Tweets into the third group. Also, used to count the total number of Tweets in each group on a particular date.

Data visualization: The data visualizer in the system is used to represent the information in the form of a chart, diagram or picture. These are depicted in results section.

Implementation details: The opinion analyzer finds the user opinion hidden inside the sentences using following three steps:

Step 1: calculation of opinion value of each sentence Step 2: vlassification of sentences into positive, negative and neutral

- Step 3: summarization and date wise counting of total Tweets in each group

Method of opinion value calculation: A corpus each of positive words and negative words are maintained. Each corpus contains more than 3000 words. Figure $3 \mathrm{a}, \mathrm{b}$ shows snapshot of positive and negative words corpus.

Firstly, every word (tw) in a Tweet (t) is compared against each item of the positive words corpus. If the word (tw) matches the words in positive words corpus the count of 'positive words (pw)' increases by 1. Similarly, if it matches the negative words corpus, the count of 'negative words (nw)' increases by 1. The process continues for all the words of all the tweets. At the end of this process, system gives total count of positive words and negative words. Finally, the score of the sentence will be calculated using Eq. 1: 
(a)

\begin{tabular}{|l|}
\hline abound \\
abounds \\
abundance \\
abundant \\
accessable \\
accessible \\
acclaim \\
acclaimed \\
acclamation \\
accolade \\
accolades \\
accommodative \\
accomodative \\
accomplish \\
accomplished \\
accomplishment \\
accomplishments \\
accurate \\
accurately \\
achievable \\
achievement
\end{tabular}

(b)

2-faced
2 -faces
abnormal
abolish
abominable
abominably
abominate
abomination
abort
aborted
aborts
abrade
abrasive
abrupt
abruptly
abscond
absence
absent-minded
absentee
absurd
absurdity

Fig. 3: Snapshot of positive and negative corpus: a) Positive words and b) Negative words

$$
\begin{array}{r}
\text { Score }(\mathrm{t})=\text { Positive words count }(\mathrm{pw})- \\
\text { Negative words count }(\mathrm{nw})
\end{array}
$$

At the end, the system stores the scores of each sentence in a corpus called 'Tweet_Scores'. For example, consider a Tweet:

"He is Suresh Tanna, a small businessman has faced great slowdown after noteban and amp; GST he has faith in it"

In this Tweet, "great" and "faith" are positive words and "slowdown" is considered as negative word:

- Total number of positive words: 2

- Total number of positive words: 1

. $\quad$ Score $(\mathrm{t})=2-1=1$

Scores for all the Tweets in the corpus will be calculated in the same way and stores in GST_Scores corpus. The snapshot of this is shown in Table 2 and 3.

Opinion classification: The system reads the scores of each Tweet from Tweet_Scores corpus. If the score of the sentence is $>0$, then the sentence is considered as "Positive sentence". If the sentence score is $<0$, then the sentence is considered as "Negative sentence". Otherwise, the sentence is considered as "Neutral Sentence". The following algorithm is applied on 'Tweet_Scores' Corpus and the system classifies the Tweets into positive, negative or neutral.
Table 2: Shaoshot of score corpus

\begin{tabular}{ll}
\hline Scores & Text \\
\hline 2 & RT @bhatia_niraj23: he is Suresh Tanna, a small businessman \\
& has faced great slowdown after noteban and amp; GST he has \\
& faith in @Office Of RG and amp \\
-2 & RT @ptrmadurai: 6 years of ADMK Govt, capped by a \\
disastrous $\quad$ GST implementation have seriously damaged TN's \\
industrial $\quad$ growth. this study \\
$0 \quad$ RT @ashokgehlot51: Five quarters of slowdown in GDP growth \\
are an indication that both \#DeMonetisation and Modi \\
government's \#GST proved to \\
$0 \quad$ RT@livemint: Gujarat elections: saurashtra traders miffed after \\
GST nixes 'kutcha' transactions https:/t.co/PJRFe5J2MC \\
$-2 \quad$ @PRSLrgislative @arunjaitley PI increase limit of income for \\
tax on salary class drastically in this
\end{tabular}

\begin{tabular}{|c|c|c|}
\hline Scores & Text & Opinion \\
\hline 2 & $\begin{array}{l}\text { RT @bhatia niraj23: He is Suresh Tanna, A small } \\
\text { businessman has faced great slowdown after noteban } \\
\text { and amp; GST he has faith in } @ \text { Office Of RG and am }\end{array}$ & Positive \\
\hline-2 & $\begin{array}{l}\text { RT@ptrmadurai: } 6 \text { years of ADMK Govt, capped by } \\
\text { a disastrous GST implementation have seriously } \\
\text { damaged TN's Industrial Growth. This study }\end{array}$ & Negative \\
\hline 0 & $\begin{array}{l}\text { RT @ashokgehlot51: five quarters of slowdown in } \\
\text { GDP growth are an indication that both } \\
\text { \#DeMonetisation and Modi government's \#GST } \\
\text { proved to }\end{array}$ & Neutral \\
\hline 0 & $\begin{array}{l}\text { RT @livemint: Gujarat elections: saurashtra treaders } \\
\text { miffed after GST nixes 'kutcha' transactions } \\
\text { https://t.co/PJRFe 5J2MC }\end{array}$ & Neutral \\
\hline & $\begin{array}{l}@ \text { PRSLrgislative @ arunjaitley PI increase limit of } \\
\text { income for tax on salary class drastically in this. }\end{array}$ & Negative \\
\hline
\end{tabular}

Table 3: Snapshot of corpus with score and opinion

Table 4: Snapshot of corpus of opinion summarizer

\begin{tabular}{lcc} 
Tweets & Created & Number \\
\hline Negative & $06 / 12 / 2017$ & 202 \\
Neutral & $06 / 12 / 2017$ & 394 \\
Positive & $06 / 12 / 2017$ & 177 \\
Negative & $07 / 12 / 2017$ & 421 \\
Neutral & $07 / 12 / 2017$ & 961 \\
Positive & $07 / 12 / 2017$ & 424 \\
Negative & $11 / 12 / 2017$ & 175 \\
Neutral & $11 / 12 / 2017$ & 618 \\
Positive & $06 / 12 / 2017$ & 219 \\
\hline
\end{tabular}

Algorithm 1; The corpus with score and its corresponding opinion:

For each Tweet(t) in Tweets Corpus

Calculate Score(t) using (1)

Opinion $=$ null

If score $(t)>0$ then

Opinion = "Positive"

Else if score $(\mathrm{t})<0$ then

Opinion = "Negative"

Else

Opinion = "Neutral"

Opinion summarization: The summarizer in the opinion analyzer counts and clusters the Tweets into 3 clusters positive, negative and neutral using the 'Tweets created date' as key. The output will be stored in GST opin Corpus. The snapshot of opinion summarizer is shown in Table 4. 


\section{RESULTS AND DISCUSSION}

Results evalution: This study deals with the results obtained by Twitter Opinion Miner. For the purpose of analysis, we collected Tweets about GST for 1 month. The sample dataset contains around 17000 Tweets about GST. Sample Tweets extracted using Twitter API is shown in Table 5 .

The output of opinion analyzer, after finding the opinion value and classifying the Tweets into "Positive, negative and neutral" is shown in Table 6. The results of opinion analyzer on sample dataset is shown in Table 7.
The various types of visualization of the results of opinion analyzer are depicted in Fig. 4 and 5. In these figures, green color denotes "Positive opinion", red color denotes "Negative opinion" and yellow color denotes "Neutral opinion".

The data visualition technique on small dataset shows the clear idea about output of Twitter opinion analyzer which is shown in Table 8 and also dipicted in Fig. 6.

Table 9 shows the over all summary of the results of opinion analyzer. The graph in Fig. 7 shows overall result analysis of opinion analyzer. The results clearly show that

Table 5: Sample Tweets extracted using Twitter API

Created Tweets

06/12/2017 RT @bhatia_niraj23: He is Suresh Tanna, A small businessman has faced great slowdown after noteban and amp; GST he has faith in @Office Of RG and amp

06/12/2017 RT @ptrmadurai: 6 years of ADMK Govt, capped by a disastrous GST implementation have seriously damaged TN's Industrial Growth. This study

06/12/2017 RT@ashokgehlot51: Five quarters of slowdown in GDP growth are an indication that both \#DeMonetisation and Modi government's \#GST proved to

06/12/2017 RT @kukk44: This is not GST, this is Gabbar Singh Tax. Its aim is to take away your hard earned money

Table 6: Output of opinion analyzer

\begin{tabular}{|c|c|c|c|c|}
\hline Tweets & Positive words count (A) & Negative words count (B) & Score $=$ A-B & Opinion \\
\hline $\begin{array}{l}\text { He is Suresh Tanna, } \\
\text { a small businessman } \\
\text { has faced great slowdown } \\
\text { after note ban and amp; } \\
\text { He has faith in GST }\end{array}$ & 2 (Great, Faith) & 1 (Slowdown) & 1 & Positive \\
\hline $\begin{array}{l}6 \text { years of ADMK Govt, } \\
\text { capped by a disastrous } \\
\text { GST implementation } \\
\text { have seriously damaged } \\
\text { TN's industrial growth }\end{array}$ & 0 & 2 (disastrous, damaged) & -2 & Negative \\
\hline $\begin{array}{l}\text { Gujarat elections: Saurashtra } \\
\text { traders miffed after GST } \\
\text { nixes 'kutcha' transactions }\end{array}$ & 0 & 0 & 0 & Neutral \\
\hline
\end{tabular}

Table 7: Results of opinion analyzer on sample dataset

\begin{tabular}{|c|c|c|c|c|}
\hline Creation date & Negative & Neutral & Positive & Grand total \\
\hline $01 / 12 / 2017$ & 166 & 409 & 129 & 704 \\
\hline $03 / 12 / 2017$ & 183 & 531 & 200 & 914 \\
\hline $05 / 12 / 2017$ & 87 & 274 & 107 & 468 \\
\hline $06 / 12 / 2017$ & 202 & 394 & 177 & 773 \\
\hline $07 / 12 / 2017$ & 421 & 961 & 424 & 1806 \\
\hline $11 / 12 / 2017$ & 175 & 618 & 219 & 1012 \\
\hline $12 / 12 / 2017$ & 204 & 421 & 198 & 823 \\
\hline $13 / 12 / 2017$ & 377 & 933 & 320 & 1630 \\
\hline $16 / 12 / 2017$ & 38 & 206 & 95 & 339 \\
\hline $17 / 12 / 2017$ & 137 & 301 & 191 & 629 \\
\hline $19 / 12 / 2017$ & 199 & 327 & 249 & 775 \\
\hline $21 / 12 / 2017$ & 277 & 615 & 322 & 1214 \\
\hline $22 / 12 / 2017$ & 376 & 1047 & 348 & 1771 \\
\hline $23 / 12 / 2017$ & 106 & 169 & 124 & 399 \\
\hline $25 / 12 / 2017$ & 113 & 266 & 110 & 489 \\
\hline $26 / 12 / 2017$ & 127 & 372 & 112 & 611 \\
\hline $27 / 12 / 2017$ & 154 & 410 & 165 & 729 \\
\hline $29 / 12 / 2017$ & 149 & 290 & 128 & 567 \\
\hline $30 / 12 / 2017$ & 157 & 316 & 101 & 574 \\
\hline $31 / 12 / 2017$ & 110 & 341 & 139 & 590 \\
\hline Grand total & 3758 & 9201 & 3858 & 16817 \\
\hline
\end{tabular}




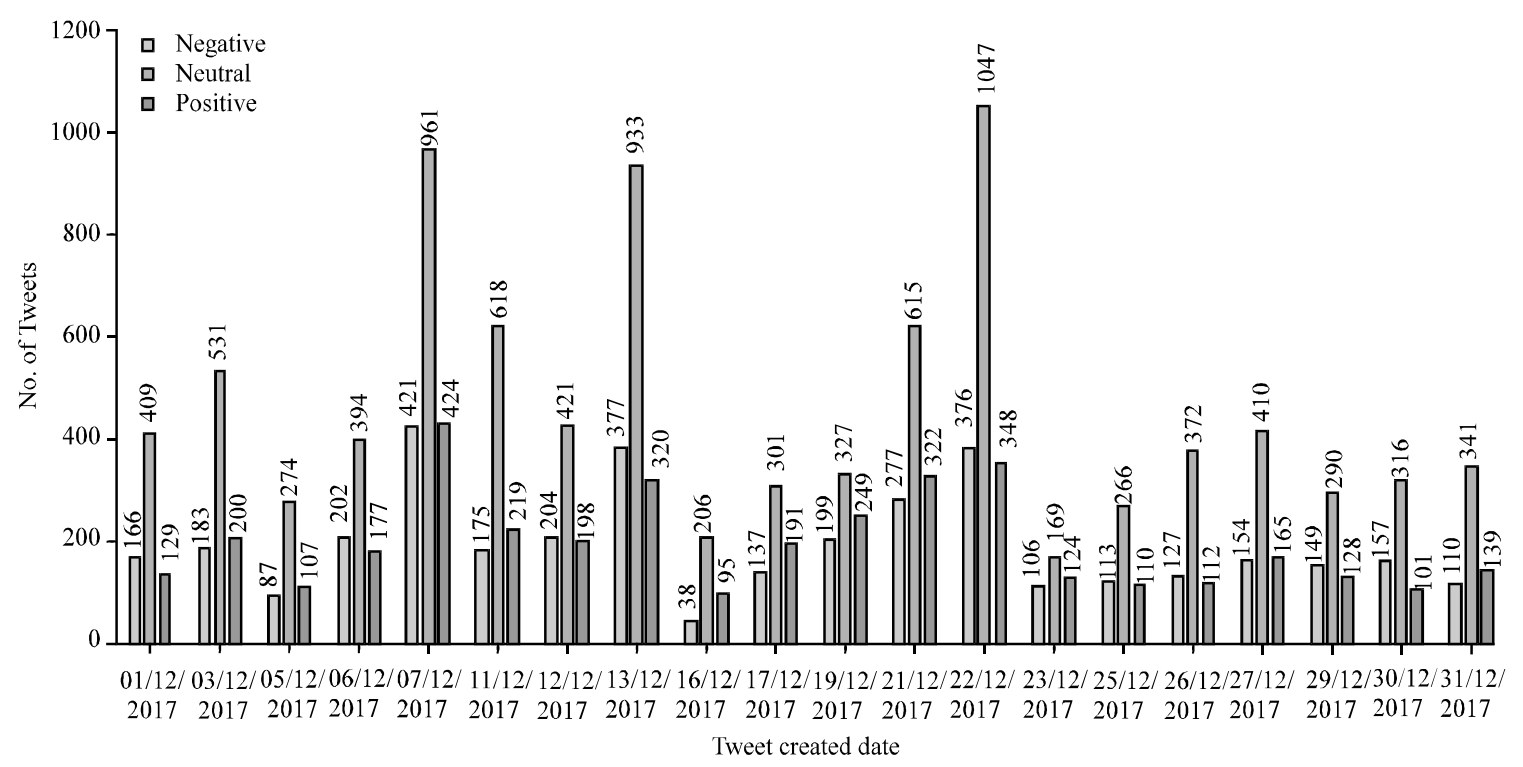

Fig. 4: Results of Twitter opinion analyzer; Public opinion on GST

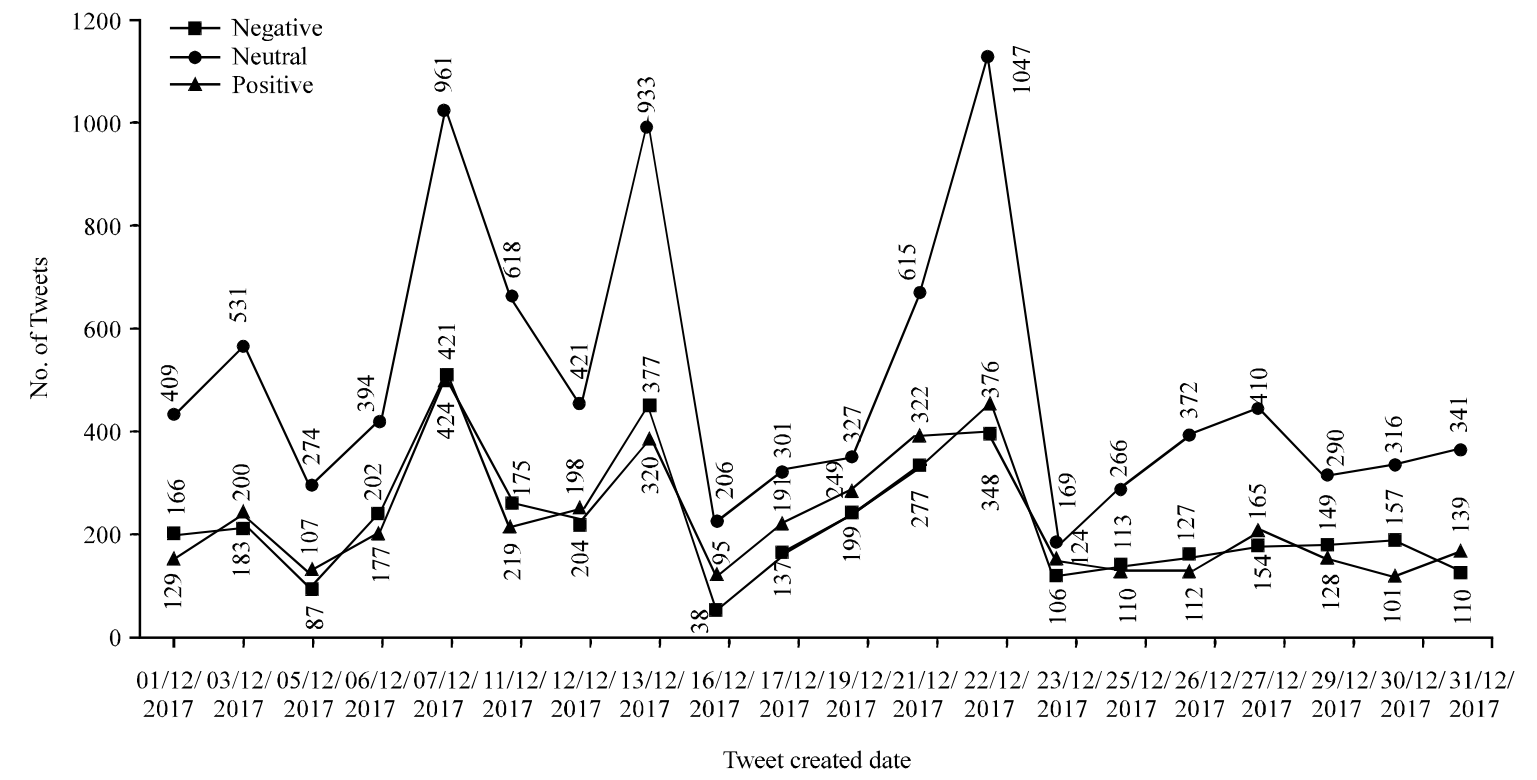

Fig. 5: Line graph representation of results; Public opinion on GST

\begin{tabular}{|c|c|c|c|c|}
\hline Row labels & Negative & Neutral & Positive & Grand total \\
\hline $01 / 12 / 2017$ & 166 & 409 & 129 & 704 \\
\hline $03 / 12 / 2017$ & 183 & 531 & 200 & 914 \\
\hline $05 / 12 / 2017$ & 87 & 274 & 107 & 468 \\
\hline $06 / 12 / 2017$ & 202 & 394 & 177 & 773 \\
\hline $07 / 12 / 2017$ & 421 & 961 & 424 & 1806 \\
\hline Grand total & 1059 & 2569 & 1037 & 4665 \\
\hline
\end{tabular}

Table 9: Summary of results

\begin{tabular}{lr}
\hline Variables & Values \\
\hline Negative & 3758 \\
Neutral & 9201 \\
Positive & 3858 \\
Total Tweets & 16817 \\
\hline
\end{tabular}

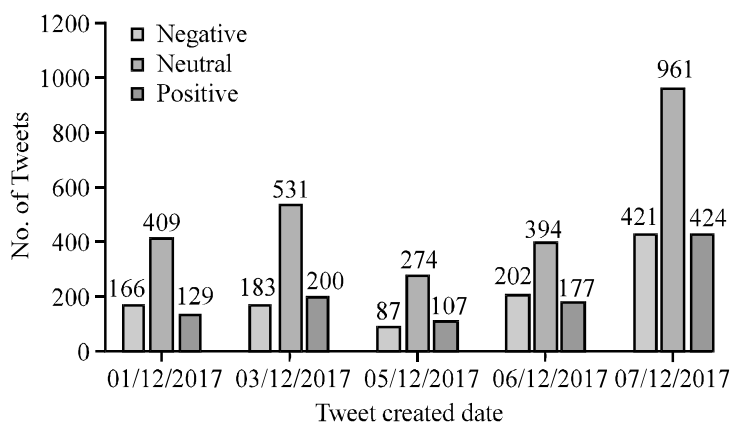

Fig. 6: Results of Twitter opinion analyzer on small dataset; Public opinion on GST 


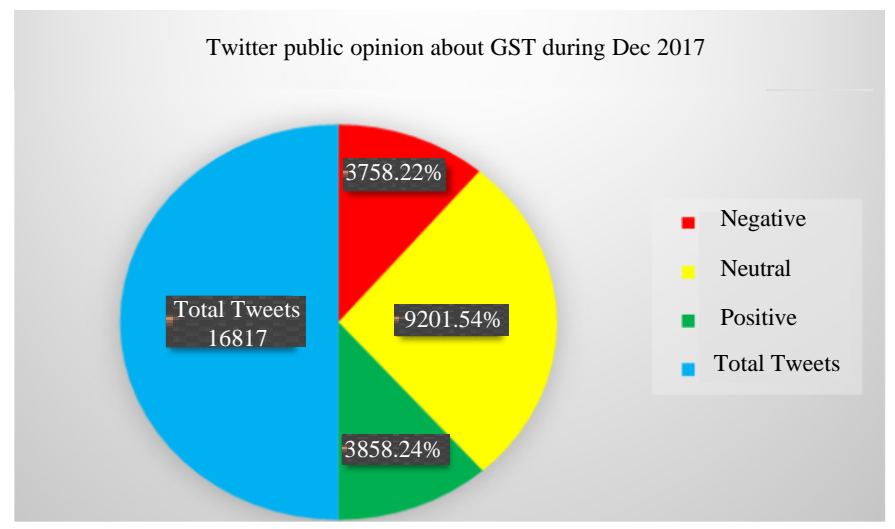

Fig. 7: Overall result analysis of Twitter opinion analyzer

$24 \%$ of users expressed positive opinion about GST. Majority of the respondents (around 54\%) had posted neutral comments about GST. The $22 \%$ of users Tweeted negatively about GST.

\section{CONCLUSION}

This study explained the various steps involved in finding user opinion and sentiments on a specific topic or event. This study explained in detail about the construction of Twitter opinion analyzer. The opinion analyzer extracts real time Tweets based on a given search term, removes noise in Tweets and constructs the corpus of sample data. Then, the opinion analyzer calculates the polarity for each sentence in the corpus. The classifier of the system finally classify the Tweets into "Positive", "Negative" and "Neutral" based on the polarity. For this research, sample Tweets on GST was collected and processed. In a 1 month span, around 17000 Tweets were collected. Opinion Classifier has classified 3758 Tweets into "Negative", 9201 tweets into "Neutral" and 3858 Tweets into "Positive". The results clearly show that $24 \%$ of users expressed positive opinion, around $54 \%$ of them had posted neutral comments and $22 \%$ of users Tweeted negatively about GST.

\section{RECOMMENDATIONS}

The rapid growth in volume, velocity, variety of data generated by social media leads to difficulties for the traditional systems with limited storage capacity and computing power. This is one of the main factors for booming of big data. Now a days, companies use big data analysis to make targeted, real-time decisions to increase profit of the business. Sentiment analysis with big data framework will help the business to find the appropriate insights and help the business in strategic decision making.

\section{ACKNOWLEDGEMENTS}

We wish to express our sincere thanks and deep sense of gratitude to all the staff members of Computer Science Department of Bharath University, Chennai for their support and co-ordination. We would also want to thank ourfriends and family members for their support.

\section{REFERENCES}

Barnaghi, P., P. Ghaffari and J.G. Breslin, 2016. Opinion mining and sentiment polarity on Twitter and correlation between events and sentiment. Proceedings of the 2016 IEEE 2nd International Conference on Big Data Computing Service and Applications (BigDataService), March 29- April 1, 2016, EEE, Oxford, UK., ISBN:978-1-5090-2251-9, pp: 52-57.

Fernandes, R. and R. D'Souza, 2016. Analysis of product Twitter data though opinion mining. Proceedings of the 2016 IEEE Annual India Conference on (INDICON), December 16-18, 2016, IEEE, Bangalore, India, ISBN:978-1-5090-3647-9, pp: 1-5.

Jansen, B.J., M. Zhang, K. Sobel and A. Chowdury, 2009. Micro-blogging as online word of mouth branding. Proceedings of the International Conference on Extended Abstracts on Human Factors in Computing Systems (CHI'09), April 04-09, 2009, ACM, Boston, Massachusetts, USA., ISBN:978-1-60558-247-4, pp: 3859-3864.

Lin, L., J. Li, R. Zhang, W. Yu and C. Sun, 2014. Opinion mining and sentiment analysis in social networks: A retweeting structure-aware approach. Proceedings of the 2014 IEEE/ACM 7th International Conference on Utility and Cloud Computing, December 8-11, 2014, IEEE, London, UK., ISBN:978-1-4799-7881-6, pp: 890-895. 
Patil, S., V. Wangikar and K. Jayamalini, 2017. Data preprocessing, sentiment analysis and NER on Twitter data. IOSR. J. Comput. Eng., 1: 73-79.

Singh, V. and S.K. Dubey, 2014. Opinion mining and analysis: A literature review. Proceedings of the 2014 5th International Conference on Confluence the Next Generation Information Technology Summit (Confluence), September 25-26, 2014, IEEE, Noida, India, ISBN:978-1-4799-4236-7, pp: 232-239.

Thowseaf, S. and M.A. Millath, 2016. A study on GST implementation and its impact on Indian industrial sectors and export. Intl. J. Manage. Res. Soc. Sci., 3: $27-30$.
Wang, L. and J.Q. Gan, 2017. Prediction of the 2017 French election based on Twitter data analysis. Proceedings of the 2017 9th International Conference on Computer Science and Electronic Engineering (CEEC), September 27-29, 2017, IEEE, Colchester, UK., ISBN:978-1-5386-3008-2, pp: 89-93.

Wu, L., T.S. Moh and N. Khuri, 2015. Twitter opinion mining for adverse drug reactions. Proceedings of the 2015 IEEE International Conference on Big Data (Big Data), October 29-Nov 1, 2015, IEEE, Santa Clara, California, ISBN:978-1-4799-9926-2, pp: 1570-1574. 